Check for updates

Cite this: RSC Adv., 2018, 8, 38065

Received 7th September 2018 Accepted 8th November 2018

DOI: $10.1039 / \mathrm{c} 8 \mathrm{ra07480a}$

rsc.li/rsc-advances

\section{Macro/microbehavior of shale rock under the dynamic impingement of a high-pressure supercritical carbon dioxide jet}

\begin{abstract}
Fei Huang (iD *ab and Bin $\mathrm{Hu}^{\mathrm{c}}$
This paper focuses on the damage of shale rock impacted by a high-pressure supercritical carbon dioxide $\left(\mathrm{SC}-\mathrm{CO}_{2}\right.$ ) jet. A well-designed apparatus was used to conduct experiments with a high-pressure SC-CO $\mathrm{C}_{2}$ jet impacting shale core plugs. The damage, including the macrofailure and the microchanges of shale samples, was analyzed. The results show that the shale cores develop grid-like fractures on the top surface, while many layered fractures were observed inside the shale cores by means of computed tomography scan. The maximum broken depth of the shale core plugs is dependent upon the combined actions of jet pressure, jet temperature and target distance. The scanning electron microscope images along with the X-ray diffraction results indicate that the shale samples are eroded by the $\mathrm{SC}-\mathrm{CO}_{2}$ jet. This erosion may further lead to the macrodamage of shale samples by reducing their mechanical strength.
\end{abstract}

\section{Introduction}

Shale gas is one of the most important alternative sources of conventional natural gas. It is known that shale gas reservoirs are characterized by low porosity and low permeability. Reservoir reconstruction must be carried out to extract shale gas. Currently, hydraulic fracturing technology is the main method for reforming shale reservoirs. However, some disadvantages may restrict the wide use of this method: (i) the high content of clay minerals in shale may cause hydrophilic expansion, ${ }^{1}$ which will cause drilling tools to jam; (ii) the shortage of water resources is another disadvantage; and (iii) the pollution of groundwater by fracturing fluid may cause harm to the environment. ${ }^{2}$ To overcome the above disadvantages, some special fracturing fluids, such as polymer microsphere emulsion ${ }^{3}$ and bio-degradable oligo, ${ }^{4}$ have received increasing attention.

SC- $\mathrm{CO}_{2}$ is a type of material in an unconventional phase state. Its density is close to liquid, while its viscosity is close to gas. ${ }^{5}$ It does not cause clay expansion in the absence of water. Meanwhile, the shale samples absorb $\mathrm{SC}^{-\mathrm{CO}_{2}}$ more easily than methane gas. This will cause the sequestration of carbon dioxide and desorption of natural gas. ${ }^{6}$ Due to the foregoing advantages, $\mathrm{SC}-\mathrm{CO}_{2}$ is considered to be an ideal fluid for jet fracturing the shale gas reservoir. ${ }^{7,8}$ Therefore, the failure laws

${ }^{a}$ Work Safety Key Lab on Prevention and Control of Gas and Roof Disasters for Southern Coal Mines, Hunan University of Science and Technology, Xiangtan, Hunan 411201, China. E-mail: fhuang@hnust.edu.cn

${ }^{b}$ Hunan Provincial Key Laboratory of Safe Mining Techniques of Coal Mines, Hunan University of Science and Technology, Xiangtan, Hunan 411201, China

${ }^{c}$ School of Resource Environment and Safety Engineering, Hunan University of Science and Technology, Xiangtan, Hunan 411201, China of shale subjected to the $\mathrm{SC}-\mathrm{CO}_{2}$ jet are of great scientific significance.

Kolle used $\mathrm{SC}_{-} \mathrm{CO}_{2}$ jets to assist coiled tubing drilling experiments. His results revealed that the $\mathrm{SC}^{-} \mathrm{CO}_{2}$ jet can effectively reduce the threshold pressure for rock breaking. ${ }^{9} \mathrm{Du}$ carried out experimental studies on the fracturing of rock with the $\mathrm{SC}_{-} \mathrm{CO}_{2}$ jet. The results also showed that the $\mathrm{SC}^{-\mathrm{CO}_{2}}$ jet can effectively reduce the rock breaking threshold pressure and cause massive rock crushing. ${ }^{10}$ Wang conducted the same experiments. ${ }^{11}$ His results demonstrated that pump pressure, jet temperature, confining pressure, jet distance, rotary speed of core samples and jet time are the main factors influencing the rock-breaking performance and efficiency. Except for the physical impacts, the research results of Li and Jing ${ }^{12}$ indicated that $\mathrm{SC}-\mathrm{CO}_{2}$ immersion will cause damage to the rock and reduce the rock's physical strength. Guo et al. ${ }^{13}$ found that the mechanical properties of shale rock soaked with $\mathrm{SC}_{-} \mathrm{CO}_{2}$ were largely dependent upon the pressure of SC- $\mathrm{CO}_{2}$. Zhang et al. ${ }^{14}$ conducted simulation experiments on $\mathrm{SC}^{-\mathrm{CO}_{2}}$ fracturing in shale. They found that fracturing using $\mathrm{SC}_{-} \mathrm{CO}_{2}$ can reduce the pressure needed to initiate fractures by more than $50 \%$. This subject was also studied by $\mathrm{Hu}$ et al. ${ }^{15}$ Lu et al. ${ }^{16}$ conducted experimental studies on the swelling of shale in supercritical carbon dioxide, which has important consequences with regard to the production of shale gas and the sequestration of $\mathrm{CO}_{2}$ in shale formations. Zhang et al. ${ }^{17}$ found that significant surface structural changes occurred in shale after saturation with $\mathrm{CO}_{2}$ and brine, and an obvious decrease in the uniaxial compressive strength of shale was observed.

Most of the above studies put their weight on the changes of shale rock subjected to static $\mathrm{SC}-\mathrm{CO}_{2}$ fluid. Although some studies have been conducted to research the impact of high- 
pressure $\mathrm{SC}-\mathrm{CO}_{2}$ jet on the changes of rock samples, few studies take shale rock as the experimental sample. This paper plans to study the failure mechanism of shale samples impacted by a SC$\mathrm{CO}_{2}$ jet at both the macroscopic and microscopic levels.

\section{Materials and methods}

\subsection{Shale samples}

Typical shale samples were collected from the Longmaxi Formation of Sichuan Basin's lower Silurian series in the southeastern Chongqing area of China. To keep in line with the actual engineering conditions, the shale samples were tested under undrained conditions. The combined test results of total organic carbon (TOC), thermal maturity $\left(R_{0}\right)$ and porosity of the shale in this region indicate that the reservoir is rich in shale gas. ${ }^{18}$ Moreover, this region has been widely considered to be China's largest and most favorable area for shale gas accumulation. ${ }^{19,20}$ X-ray diffraction (XRD) analysis shows that the mineral components of the shale mainly consist of quartz, lay minerals (including chlorite, kaolinite and illite), calcite and dolomite. The mass percentages of these components are $52 \%$, $27 \%, 11 \%$ and $9 \%$, respectively.

The shale samples were first collected from the outcrop, and then the core plugs were drilled with water from these large blocks of shale. The size of the core plug is 100 millimeters in diameter and 150-250 millimeters in length. Computerized tomography (CT) can be utilized to obtain the internal characteristics of the rock in a nondestructive manner. ${ }^{21}$ Fig. 1 shows the CT images of the shale core plugs. According to the CT images, it can be observed that the bedding of the shale is well developed. Multiple bedding planes are approximately parallel to each other.

\section{2. $\mathrm{SC}-\mathrm{CO}_{2}$ jet impacting rock apparatus}

The experimental SC- $\mathrm{CO}_{2}$ jet breaking rock apparatus consists of four independent units: a storage unit, a modulation unit, a rock breaking unit, and a recovery unit. The storage unit mainly consists of a $\mathrm{CO}_{2}$ tank and a $\mathrm{CO}_{2}$ supplement device. It is used for the long-term storage of liquid $\mathrm{CO}_{2}$. The $\mathrm{CO}_{2}$ pressure in the container is kept in 3.0-5.0 MPa. The temperature in the tank is kept within a range of -15 to $5{ }^{\circ} \mathrm{C}$. The $\mathrm{CO}_{2}$ supplement device can complement the loss of $\mathrm{CO}_{2}$ during the experiments. The modulation unit mainly consists of a plunger pump and a heater. First, the liquid $\mathrm{CO}_{2}$ is pumped out from the tank and pressurized to the experiment's required pressure. Then, it is heated to the required temperature. Using the above procedure, supercritical $\mathrm{CO}_{2}$ can be created. The experimental unit is illustrated schematically in Fig. 2. It is primarily used to form the SC- $\mathrm{CO}_{2}$ jet and to conduct rock breaking experiments. After modulation, the supercritical $\mathrm{CO}_{2}$ enters the main unit of the rock breaking system through the wellbore inlet. Then, the SC$\mathrm{CO}_{2}$ is jetting out from the nozzle. The $\mathrm{SC}-\mathrm{CO}_{2}$ jet will impact the rock cores at the bottom. Finally, the $\mathrm{SC}-\mathrm{CO}_{2}$ will flow into the next unit through the outlet. The recovery unit consists of a solid separator, a liquid separator and a refrigerator. Its main functions are to separate $\mathrm{CO}_{2}$ from the rock debris mixture after the experiments (i.e., to remove debris, water and other impurities). Then, the clean $\mathrm{CO}_{2}$ is converted to liquid form and transported back to the $\mathrm{CO}_{2}$ tank.

\subsection{Experimental procedure}

This experiment is mainly intended to study the influence of the pump pressure on the rock-breaking performance. Based on the threshold pressure ${ }^{22}$ required for rock breaking, pump pressures of $30,35,40,45,50$, and $55 \mathrm{MPa}$ are selected as the experimental pressures. To maintain the supercritical phase of $\mathrm{CO}_{2}$, the temperature of the heater is a variable ranging from $35{ }^{\circ} \mathrm{C}$ to $80{ }^{\circ} \mathrm{C}$. The nozzle with an outlet diameter of 2 millimeters is selected. An optimal target distance range of $1 \mathrm{~mm}$ to $12 \mathrm{~mm}$ is selected according to the findings of Du et al. ${ }^{10}$ The experimental time was set to 3 minutes for each experimental pressure. Fig. 3 shows the pump pressure changing processes over time. This demonstrates that each experimental pressure sustains approximately 3 minutes. Plunger pump 1 is selected to pressurize the liquid $\mathrm{CO}_{2}$. In this experiment, we assume that the embedded depth of shale rock is about $400 \mathrm{~m}$ and the mean density is about $2000 \mathrm{~kg} \mathrm{~m}^{-3}$. So a confinement pressure of $8 \mathrm{MPa}$ is selected to monitor the deep condition of shale rock. The detailed test parameters are listed in Table 1.

Firstly, the shale core was wrapped with a Teflon tube. A heat gun was used to shrink the Teflon material in order to keep the shale core wrapped tightly enough. Then the wrapped core was put into the core holder as shown in Fig. 2. Plenty of hydraulic fluid was pumped into the gaps between core holder and Teflon tube until the confinement pressure climbed to $\sim 8 \mathrm{MPa}$. This

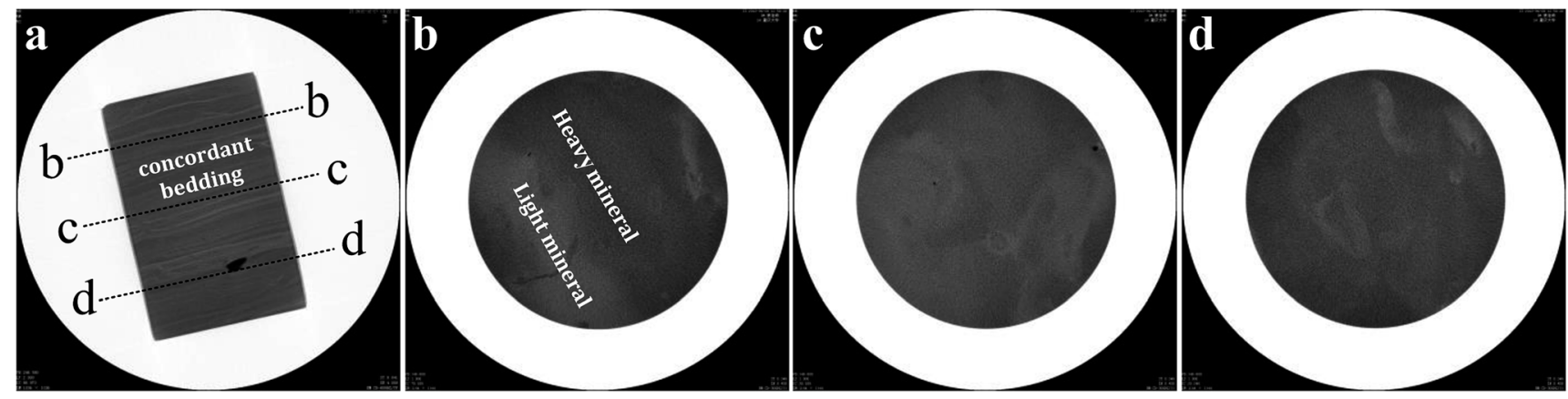

Fig. 1 CT images of shale core plugs. 


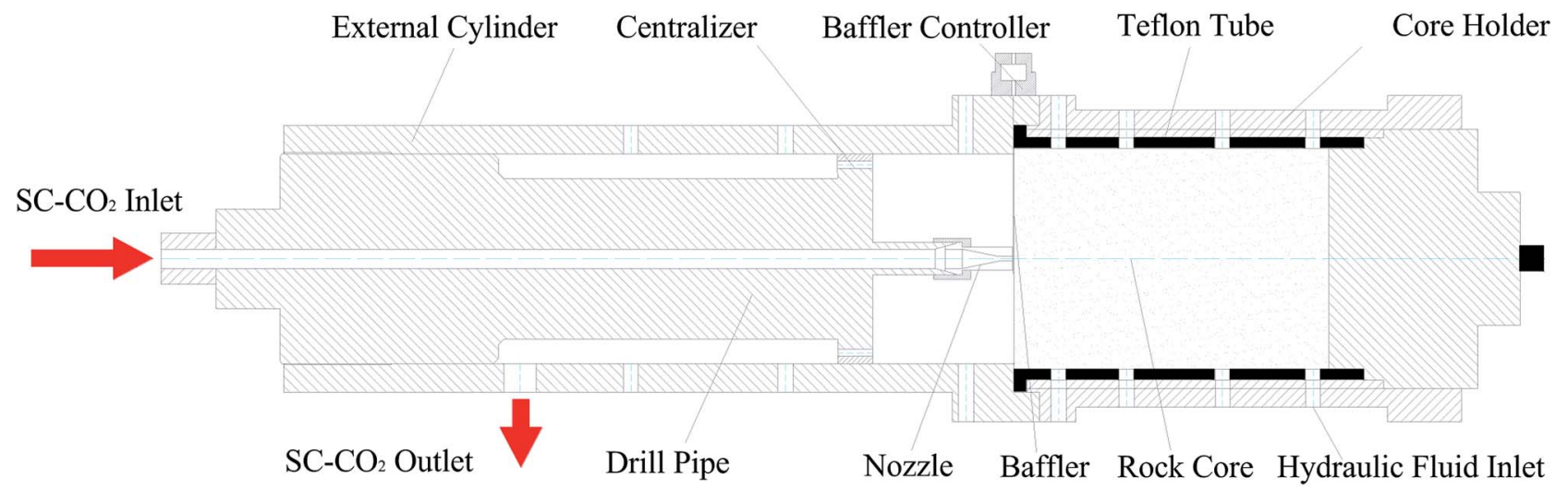

Fig. 2 Schematic diagram of the $\mathrm{SC}-\mathrm{CO}_{2}$ jet impacting rock apparatus.

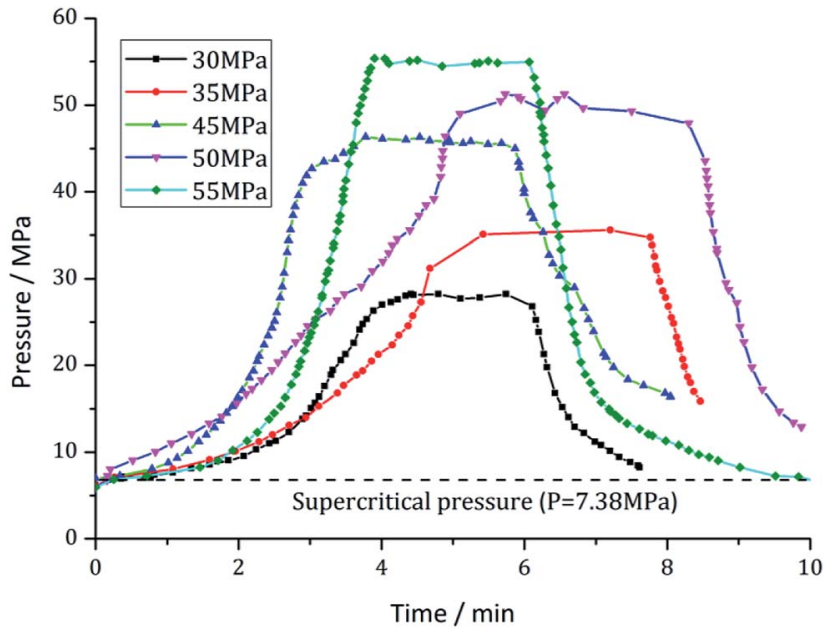

Fig. 3 The changing curves of pump pressures over time.

confinement pressure can prevent the incursion of $\mathrm{SC}^{-\mathrm{CO}_{2}}$ of which the pressure in the annular space was measured much lower than $\sim 5 \mathrm{MPa}$. Thirdly, the baffler was withdrawn and the SC$\mathrm{CO}_{2}$ jet impacted onto the top surface of shale core. After the impacting, the wrapped shale core was taken down for further test.

\section{Results and discussions}

\subsection{The macrofailure of shale}

Fig. 4 and 5 show the pictures of shale core plugs impacted by the SC- $\mathrm{CO}_{2}$ jet. It presents a grid-like fragmentation phenomenon on the top surface. When the pump pressure is $30 \mathrm{MPa}$, no crack appears on the core's end face. Increasing the pump pressure to over $35 \mathrm{MPa}$, some tiny cracks form in the central area. These initial cracks then extend along the radial direction to the free surface. Multiple cracks connect to each other during crack propagation. Then, cracks in the grid pattern appeared, as shown in Fig. 4. This grid-crack phenomenon becomes increasingly obvious with increasing pump pressure. Finally, shale core plugs may suffer from grid-like massive fracture morphology. From the macroscopic phenomenon in Fig. 4, it can be obtained that the threshold pressure of the shale breaking by the $\mathrm{SC}^{-\mathrm{CO}_{2}}$ jet is approximately between 30 and $35 \mathrm{MPa}$.

Computed tomography (CT) scan images show that multiple transverse cracks are generated inside the shale cores shown in Fig. 5. These cracks are parallel to the shale bedding. It is analyzed that they may be caused by the stress waves induced by the impact of the $\mathrm{SC}-\mathrm{CO}_{2}$ jet. Once the transverse cracks extend through the rock, the shale debris will be peeled off. Then, the shale core plugs will present what is known as the mass-broken morphology shown in Fig. 4. This morphology is identical to that described in the existing literature. ${ }^{\mathbf{8 , 1 1}}$

Giving a certain pump pressure, the rock damage will roughly extend to a maximum depth $(\Delta h)$. Fig. 6 indicates that the damage depth increases linearly with the increasing pump pressure. A linear relationship between $\Delta h$ and pressures can be described as follows:

$$
\Delta h=-64.4+2.2 P
$$

where $P$ is the pump pressure. The fitting correlation coefficient of the formula is $R^{2}=0.9878$. From eqn (1), it can be inferred

Table 1 Summary of the test constant and variables

\begin{tabular}{|c|c|c|c|c|c|c|c|c|}
\hline $1 \#$ & 30 & 191 & 100 & $150-200$ & 3 & 6 & 50 & 8 \\
\hline $3 \#$ & 40 & 229 & 100 & $150-200$ & 3 & 6 & 50 & 8 \\
\hline $4 \#$ & 45 & 247 & 100 & $150-200$ & 3 & $1 / 3 / 6 / 9 / 12$ & 50 & 8 \\
\hline $5 \#$ & 50 & 264 & 100 & $150-200$ & 3 & 6 & $35 / 40 / 45 / 50 / 55$ & 8 \\
\hline
\end{tabular}



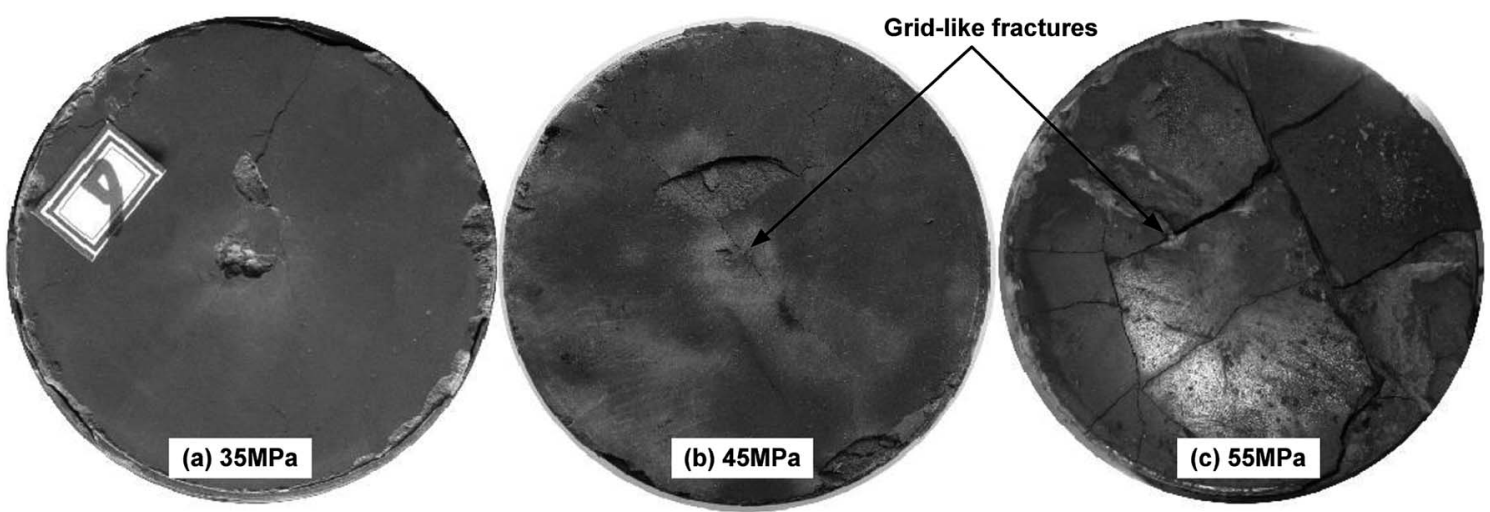

Fig. 4 Pictures of head faces of shale-cores impacted by $\mathrm{SC}-\mathrm{CO}_{2}$ jet with different pump pressures.



Fig. 5 Failure of shale cores on the side face: (a) is the picture and (b) is the CT image.

that the critical pump pressure for shale breaking is approximately 29.3. As comparison, the experimental results by Wang et al. ${ }^{11}$ and Du et al. ${ }^{23}$ are also presented in Fig. 6 . For the same pressure of $\mathrm{SC}-\mathrm{CO}_{2}$ jet, the broken depths of shale cores are much larger than those of marble cores but much smaller than those of man-made cores. It's analysed that this discrepancy is mainly caused by the combined actions of the mechanics strength and micro structures. In detailed, the compressive strength of the shale sample in this paper is about $45 \mathrm{MPa}$ which is just between that of the man-made sample (25 MPa) and the marble sample ( $\sim 65 \mathrm{MPa})$. In addition, the micro structure, such as the bedding and the grain composition, etc. is another key factor. On the whole, the broken depths are all approx-linearly increasing with the pressures of $\mathrm{SC}^{-\mathrm{CO}_{2}}$ jet. On the other hand, the contrast experiments in Fig. 6 present that the broken depth of man-made cores by water jet is quite smaller than that by $\mathrm{SC}_{-} \mathrm{CO}_{2}$ jet at the same pressure, which indicates that the rock breaking ability of $\mathrm{SC}-\mathrm{CO}_{2}$ jet is much more obvious than that of the water jet.

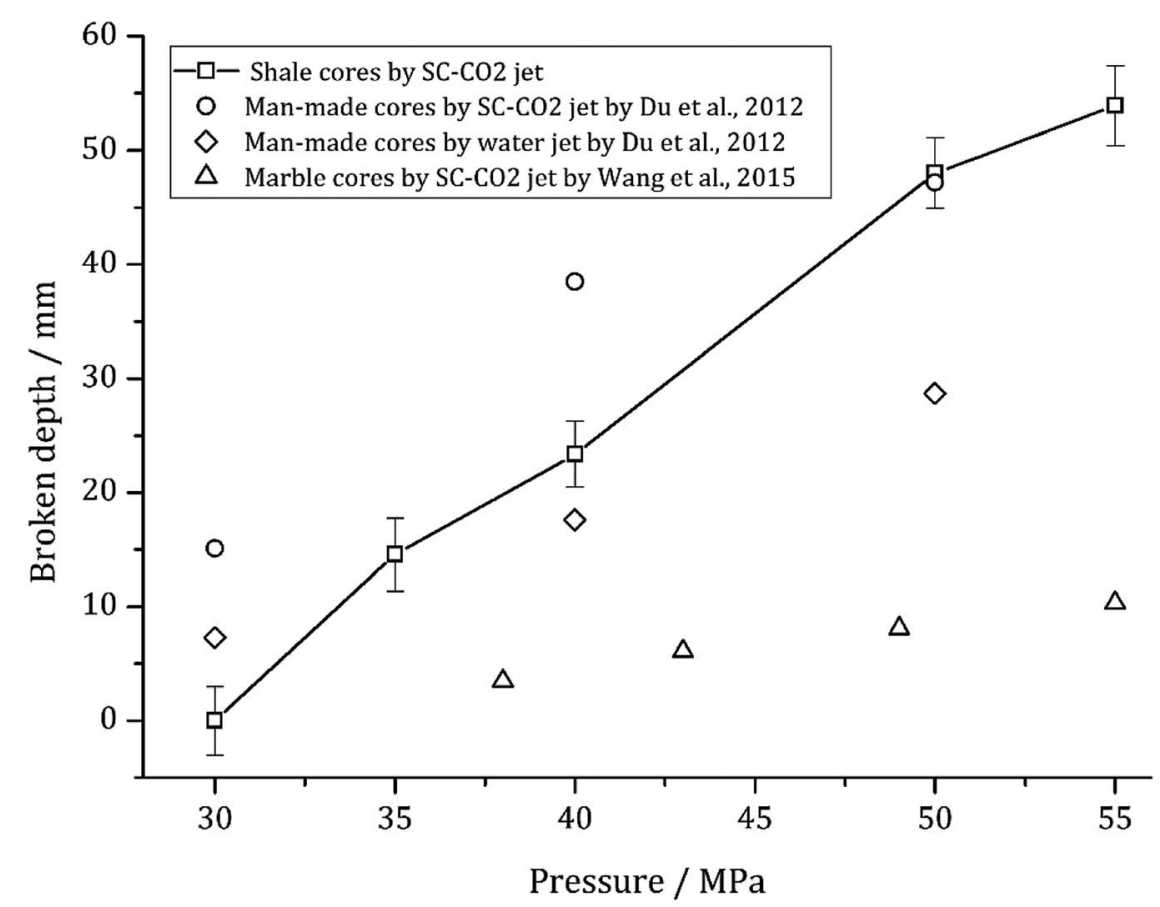

Fig. 6 Curves of broken depth and broken volume vs. pump pressure. 
Fig. 7 illustrates the influence of target distance and temperature on the maximum broken depth of shale core plugs. Here, the target distance is defined as the axial distance between the $\mathrm{SC}-\mathrm{CO}_{2}$ jet outlet and the head surface of the shale core. The special experimental temperature is controlled by attemperation of the heater. A linearly increasing relationship between the maximum broken depth and the temperature is exhibited in Fig. 7. This trend indirectly indicates that the impact performance of the $\mathrm{SC}-\mathrm{CO}_{2}$ jet is positively dependent upon the temperature of the supercritical fluid. The maximum broken depth initially increases sharply with increasing target distance. However, it climbs to a peak value when the target distance increases to approximately $6 \mathrm{~mm}$, above which the broken depth decreases with the target distance. This nonlinear relationship reveals that there may exist an optimal target distance giving a certain nozzle diameter. The impact performance of $\mathrm{SC}-\mathrm{CO}_{2}$ is most obvious at this distance. This trend can be explained by the structure of submerged jet. As known, the $\mathrm{SC}-\mathrm{CO}_{2}$ jet in this paper is a submerged jet. Its edge diffuses outwards after jetting from nozzle exit. Hence the diameter of jet will increase along the jet axis. On the other hand, the mean velocity of jet decreases from nozzle exit. Then the impact force is the product of cross-sectional area multiply by jet pressure which is proportional to the square of mean velocity. Giving the condition of jet diameter increasing while mean velocity decreasing at the same time, there may exist a point where the impact force is most large. In this experiment, a distance of about three times of the nozzle outlet diameter is found to be the optimal one. But this optimal target distance can be changeable with the jet diameter.

\subsection{The microchanges of shale}

Fig. 8 shows the scanning electron microscope (SEM) images of the shale samples before and after erosion with a magnification of 2000 times. According to the SEM images, quartz, calcite and some other minerals compose the basic skeleton of the shale. The clay minerals and other organic matter fill the voids. A small number of medium and large pores with sizes between 0.1 and 5 $\mu \mathrm{m}$ are observed (Fig. 8(a)). After erosion by the $\mathrm{SC}-\mathrm{CO}_{2}$ jet, the microscopic structure of the shale is significantly damaged. In detail, the amounts of clay mineral, organic matter and other filling materials are significantly reduced. The original pores are no longer obvious. Overall, the shale sample shows a disordered microstructure after erosion by $\mathrm{SC}-\mathrm{CO}_{2}$ jet (Fig. 8(b)).

Two factors may account for the microstructure change. First, the impact load of the SC- $\mathrm{CO}_{2}$ jet acts as a key factor. The process of high-speed fluids impacting solids can be divided into two typical stages: the water hammer pressure stage and the stagnation pressure stage. ${ }^{24}$ The water hammer pressure is usually dozens of times the stagnation pressure and is generally accepted as the cause of crack initiation. It can be described by the following expression without consideration of the tiny deformations of the solid: ${ }^{25}$

$$
P_{\mathrm{w}}=\rho C v
$$

where $P_{\mathrm{w}}$ is the water hammer pressure in MPa, and $\rho, C$ and $v$ are the fluid density, the velocity of the shock wave and the fluid velocity, respectively. According to eqn (2), the water hammer pressure of the $\mathrm{SC}-\mathrm{CO}_{2}$ jet can reach a magnitude of nearly $200 \mathrm{MPa}$ when the pump pressure is $30 \mathrm{MPa}$ (Table 2). This huge impact pressure is sufficient to crush the shale's mineral structure, resulting in physical damage to the original ordered microstructure. Therefore, the impact pressure may be the main factor for the disorder of shale's microstructure.

Second, $\mathrm{CO}_{2}$ is corrosive in the presence of water. SEM studies show that $\mathrm{CO}_{2}$ can cause significant corrosion damage

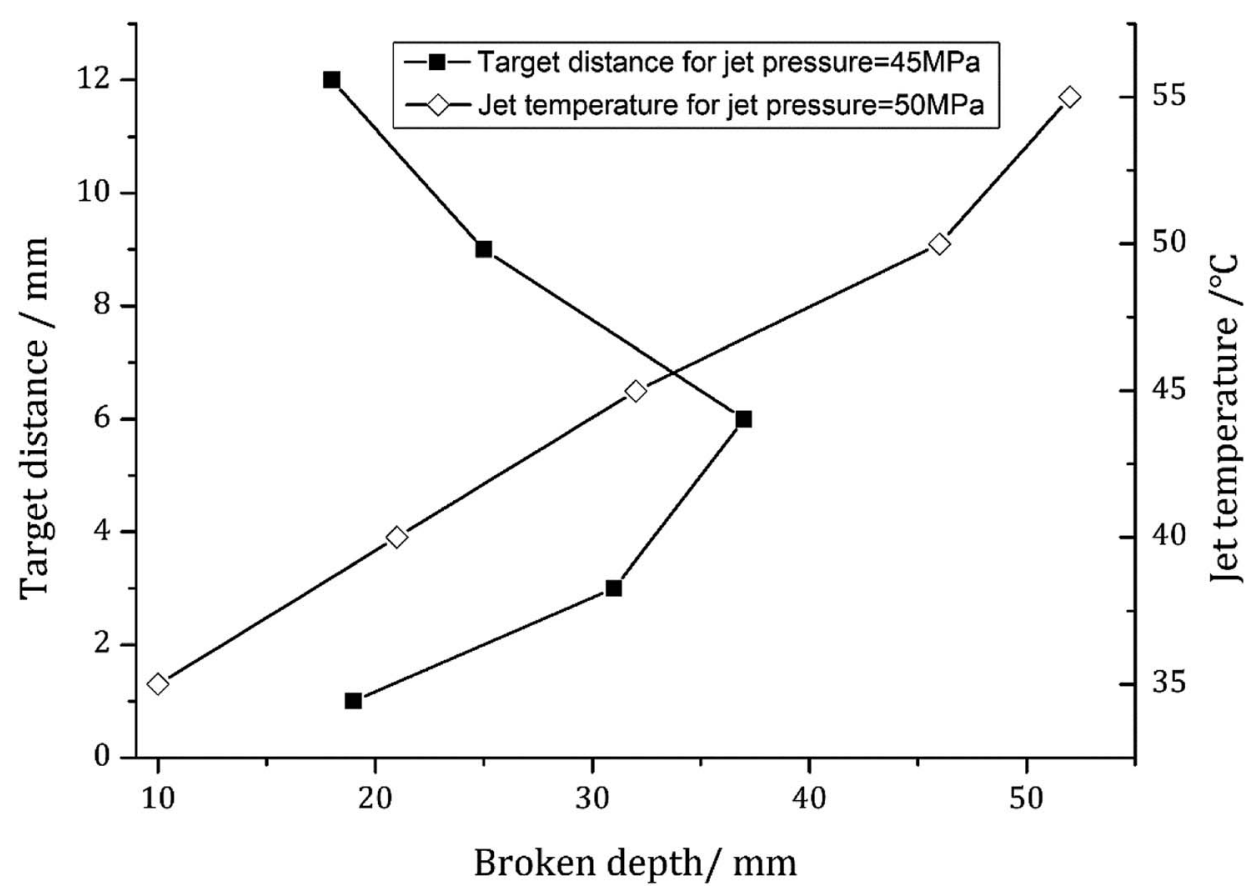

Fig. 7 Curves of broken depth vs. target distance and temperature. 




Fig. 8 SEM images of original shale (a) and eroded shale (b).

Table 2 The percentage component of shale samples by means of $X$-ray fluorescence method

\begin{tabular}{lllllllll}
\hline Shale samples & $\mathrm{SiO}_{2}$ & $\mathrm{Al}_{2} \mathrm{O}_{3}$ & $\mathrm{Fe}_{2} \mathrm{O}_{3}$ & $\mathrm{~K}_{2} \mathrm{O}$ & $\mathrm{MgO}$ & $\mathrm{TiO}_{2}$ & $\mathrm{SO}_{3}$ & $\mathrm{CaO}$ \\
\hline Original shale & 71.0364 & 14.9380 & 5.5275 & 3.9739 & 2.1151 & 1.1079 & 0.5372 \\
Eroded shale & 70.0282 & 14.0077 & 5.4708 & 4.2188 & 1.6983 & 1.2722 & 0.5847 & 1.7832 \\
\hline
\end{tabular}

to shale samples in high-pressure environments. ${ }^{26}$ This shows that $\mathrm{CO}_{2}$ mainly acts on clay minerals and organic matter. The literature $^{27}$ shows that the organic matter inside the shale decomposes upon exposure to $\mathrm{SC}-\mathrm{CO}_{2}$. Finally, the decomposition ingredients may block the original medium/large pores. Another literature ${ }^{28}$ also shows that $\mathrm{SC}-\mathrm{CO}_{2}$ acts on the kerogen and causes the decomposition of organic debris during the extraction of petroleum from oil shale by means of supercritical fluid extraction. It is known that the activity of $\mathrm{SC}^{-\mathrm{CO}_{2}}$ can be greatly enhanced in a high-temperature and high-pressure environment. This may promote the decomposition of organic matter in the shale while blocking the original pores and thus reducing the physical strength of the shale. ${ }^{29} \mathrm{~A}$ contrast experiment was conducted to measure the mechanics change between natural and $\mathrm{SC}-\mathrm{CO}_{2}$ eroded shale samples at the same condition as in this paper. ${ }^{30}$ It's presented that the tensile strength of shale sample eroded by SC- $\mathrm{CO}_{2}$ decreases by $18.3 \%$ and the triaxial compressive strength by $8.3 \%$ respectively. Hence, it can be inferred that the erosion of $\mathrm{SC}^{-} \mathrm{CO}_{2}$ fluid can reduce the mechanics strength of shale sample by changing its microstructure.

According to the above references, the clay minerals in shale may decompose as a result of the corrosion of $\mathrm{SC}^{-\mathrm{CO}_{2}}$. Fig. 9 shows the XRD spectra of the shale samples. After erosion by the $30 \mathrm{MPa} \mathrm{SC}-\mathrm{CO}_{2}$ jet for $3 \mathrm{~min}$, there was no change in the clay contents; after erosion by the $55 \mathrm{MPa} \mathrm{SC}_{-} \mathrm{CO}_{2}$ jet for $3 \mathrm{~min}$, the contents of illite and clinochlore decreased significantly, as shown in Fig. 9a. The $\mathrm{CO}_{2}$ reacted with the pore water, and the carbonic acid generated. Under high-temperature and highpressure conditions, the acidic environment will cause the decomposition of illite and clinochlore. ${ }^{31}$ In addition to the decomposition of clay minerals, an obvious decrease of dolomite can be observed according to the XRD spectra, as shown in Fig. $9 \mathrm{~b}$.

In natural shale gas reservoirs, the decomposition reaction of clay minerals affected by $\mathrm{CO}_{2}$ may take a long time, even as long as several years. In this experiment, the decomposition duration of the clay minerals is significantly shortened. First, the physical impact of the high-speed $\mathrm{SC}-\mathrm{CO}_{2}$ jet may lead to the rapid decomposition of clay minerals. Then, the high temperature can accelerate the reaction of $\mathrm{CO}_{2}$ with clay minerals. ${ }^{32,33}$ However, due to the relatively short duration of the experiments, the decomposition of the clay minerals may not be complete, and changes of other minerals are not observed by semiquantitative XRD analysis.

X-ray fluorescence was used to analyze the changes of the shale components before and after the $\mathrm{SC}^{-} \mathrm{CO}_{2}$ jet impacting. The exact percentage of some major component of shale samples is illustrated in Table 2. Fig. 10 is the histogram showing the contrast of components in shale samples before and after the SC$\mathrm{CO}_{2}$ jet impacting. The obvious decreases of aluminum oxide and magnesium oxide are observed in the histogram. These two oxides are the main components of clay minerals. The changes of these two oxides further strengthen the finding of clay mineral decomposition after the $\mathrm{SC}-\mathrm{CO}_{2}$ jet impacting. However, a large increase in calcium oxide is observed in Fig. 10. This increase has 

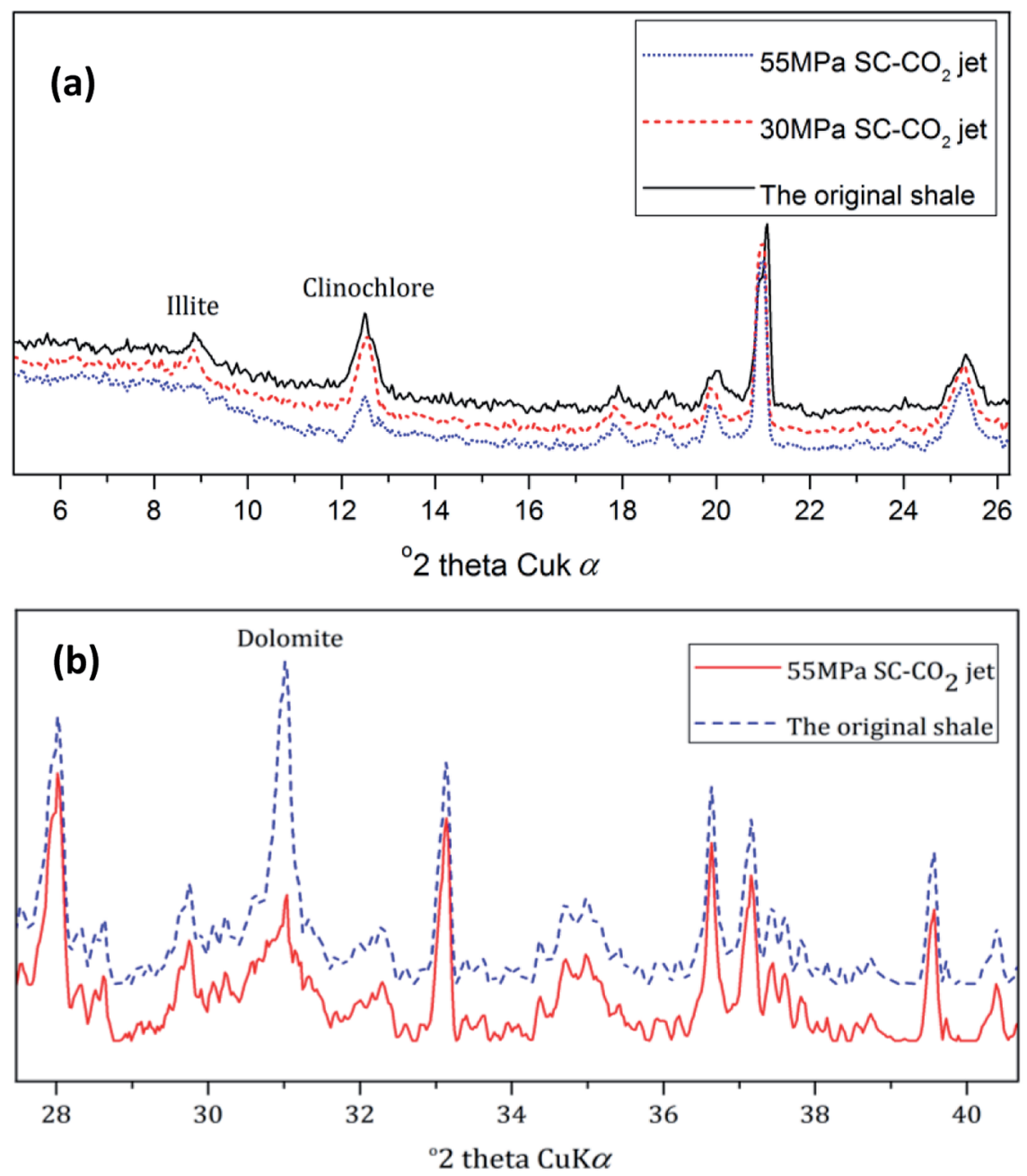

Fig. 9 Bulk XRD plot of the original shale and the eroded shale.

a close connection with the adsorption of carbon by shale samples, which is discussed in detail in the following section.

\subsection{The adsorption of carbon on the shale surface}

According to Fig. 4, multiple radial cracks were generated on the top surface. Along the radial cracks, multiple samples were selected equidistantly to test the carbon content. The relationship between the carbon content and the radial distance is shown in Fig. 11. A nonlinear fitting of the test data is shown in Fig. 11. It can be expressed as follows:

$$
\operatorname{Pr}=0.56+\frac{7.24}{1+\exp \left(20 \times\left(r / r_{0}-0.43\right)\right)}
$$

where $r$ is the radial distance and $r_{0}$ is the radius of the shale core. The fitting correlation coefficient of the formula is $R^{2}=0.9687$. According to the changing tendency of carbon content, the top surface can be divided radially into three areas. The circle from center to $0.25 r_{0}$ is Area I. The average carbon content in this area is relatively high (i.e., as high as $8 \%$ ). It decreases slightly with increasing radial distance. Then, the annulus from $0.25 r_{0}$ to $0.6 r_{0}$ is Area II. The average carbon content in this area decreases rapidly with increasing radial distance. The annulus from $0.6 r_{0}$ to $r_{0}$ is Area III. The average carbon content in this area is relatively low. Within Area III, the carbon content tends to be a constant.

The change in carbon content indicates that the shale can absorb $\mathrm{CO}_{2}$. A large number of studies have shown that shale has sequestration characteristics for supercritical, gaseous and liquid $\mathrm{CO}_{2}{ }^{31,34,35}$ In previous experimental studies, $\mathrm{CO}_{2}$ acted on shale in static form. The action duration of the $\mathrm{CO} 2$ was relatively longer. However, in this experiment, $\mathrm{CO}_{2}$ was in the form of supercritical jets. In Fig. 10, Area I is the direct erosion area of the $\mathrm{SC}-\mathrm{CO}_{2}$ jet. Area II is the action area of the $\mathrm{SC}-\mathrm{CO}_{2}$ radial jet. Lastly, Area III is the action area of the $\mathrm{SC}^{-\mathrm{CO}_{2}}$ back flow. According to the test data, the carbon content increases significantly when subjected to the direct erosion of the $\mathrm{SC}-\mathrm{CO}_{2}$ jet. This indicates that the interaction between the $\mathrm{SC}^{-} \mathrm{CO}_{2}$ jet and the shale sample contributes to the adsorption of $\mathrm{CO}_{2}$ in shale.

\section{Discussion}

According to the studies by Kolle and Du et al., the method of rock breaking by $\mathrm{SC}-\mathrm{CO}_{2}$ jet has the advantages of low threshold 


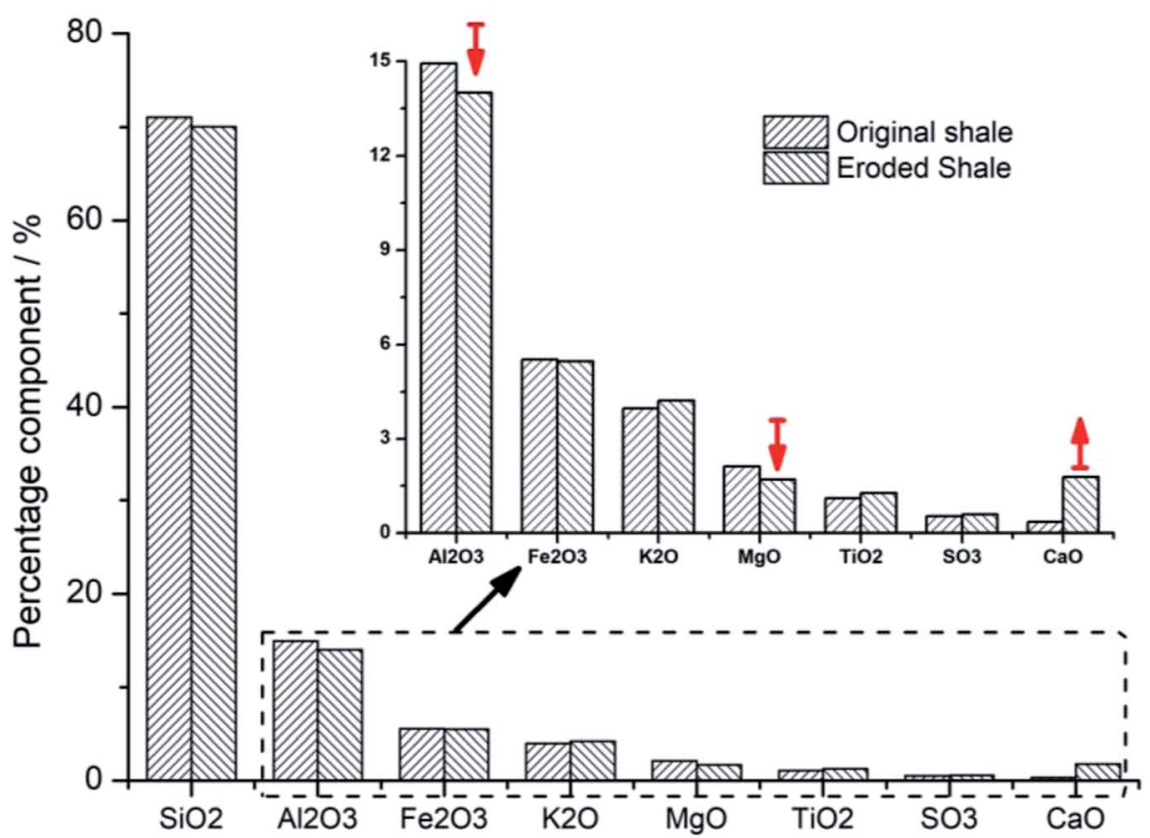

Fig. 10 Contrast of components in shale samples before and after the $\mathrm{SC}-\mathrm{CO}_{2}$ jet impacting.

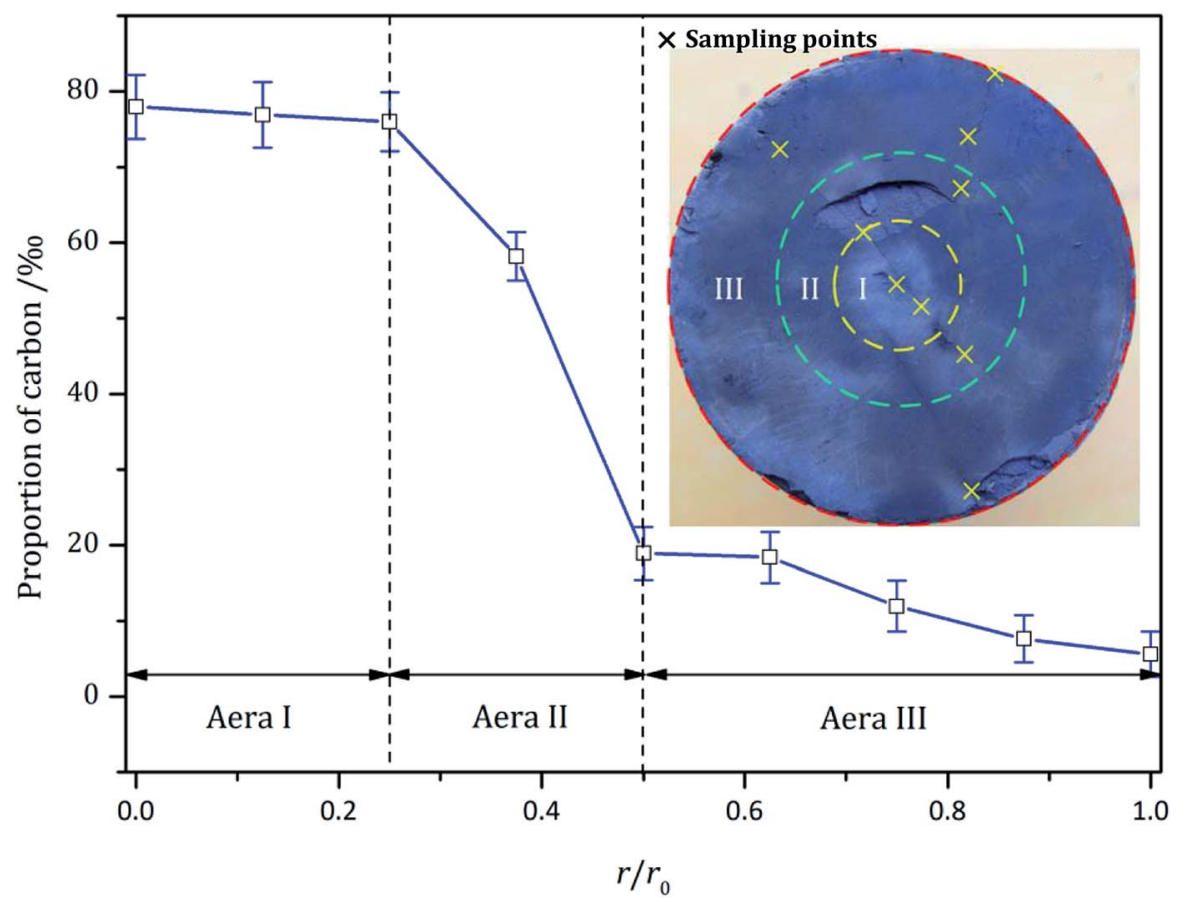

Fig. 11 Proportions of carbon on the head face of shale-core.

pressures and volume breakage. ${ }^{\mathbf{8 1 0}}$ It is inferred that the combined action of three main factors may cause the shalebreaking phenomenon. They are the jet impact load, the corrosion properties of $\mathrm{CO}_{2}$ at high-temperature and under high-pressure conditions, and the bedding characteristics of shale.

First, the impact load of the $\mathrm{SC}-\mathrm{CO}_{2}$ jet is the dominant factor leading to shale breakage. It is known that the water hammer pressure induced at the initial stage by the impact load spreads radially in the form of stress waves. These waves include the Rayleigh wave and the body wave (i.e., longitudinal and transverse waves). ${ }^{36,37}$ According to eqn (2), the water hammer pressure can reach a magnitude near 0.2 GPa (Table 2). On the shale surface, the Rayleigh waves produce a shear stress component and a tensile stress component. ${ }^{38}$ These large shear stress components and tensile stress components first induce 

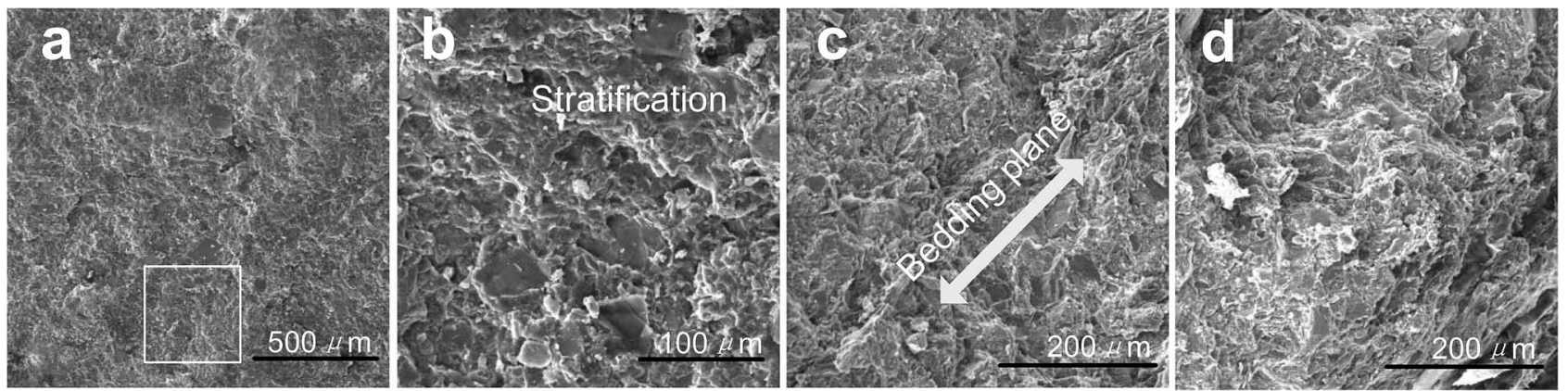

Fig. 12 SEM images of fracture surface of shale samples; (a) and (b) are the surface of transverse fractures with the magnification of $\times 100$ and $\times 500$; (c) and (d) are the surface of longitudinal fractures with the magnification of $\times 300$ and $\times 300$.

the generation of initial cracks on the shale surface. As a result, the propagation of Rayleigh waves may account for the grid-like fragmentation phenomenon on the shale surface.

Second, the water hammer pressure spreads inside the shale in the form of spherical stress waves. It is known that the reflection of waves could enhance the tensile stress in certain areas inside the shale. The tensile strength of the shale is much lower than the compressive strength (Table 1). Therefore, initial cracks will be generated in these enhanced areas. Then, it can be observed that multiple beddings are nearly parallel to each other from the CT images in Fig. 1. These beddings further weaken the tensile strength of the shale sample and cause the initial cracks to extend along the bedding planes under tensile stress. This is the direct cause for the macroscopically visible transverse cracks seen in Fig. 5. The SEM method is applied to investigate the foregoing assumptions. It can be observed from the SEM images that the surfaces of transverse cracks are stratified. This stratification agrees with the typical character of tensile fracture (Fig. 12(a) and (b)). On the other hand, the surfaces of longitudinal cracks are disordered (Fig. 12(c) and (d)). These cracks may be the result of shear stress.

Third, from the SEM images and XRD semiqualitative analysis, it can be seen that $\mathrm{SC}-\mathrm{CO}_{2}$ fluid has changed the microscopic structures and the component compositions of shale material. Therefore, it can be inferred that the physical and mechanical strength of shale samples could be weakened after erosion. Shale erosion occurs in the area where it is directly subjected to the $\mathrm{SC}-\mathrm{CO}_{2}$ jet. Thus, the breakage of shale samples in this area is much easier. The grid-like fragmentation phenomenon may be the result of erosion.

\section{Conclusions}

According to the experimental studies, $\mathrm{SC}-\mathrm{CO}_{2}$ jet could effectively promote the decomposition of clay minerals. Meanwhile, the jet impact could change the microstructures of shale samples. According to the change laws of carbon content on the shale surface, the shale sample could absorb supercritical $\mathrm{CO}_{2}$. The shale sample takes on the phenomenon of massive layered breakage subjected to the $\mathrm{SC}-\mathrm{CO}_{2}$ jet. This could be caused by the following key factors. First, the stress wave induced by the dynamic load of the $\mathrm{SC}-\mathrm{CO}_{2}$ jet impact is the dominant factor.
Then, the erosion of shale samples by $\mathrm{SC}^{-\mathrm{CO}_{2}}$ under highpressure and high-temperature environments is an auxiliary factor. Third, the parallel bedding feature of the shale sample is the internal factor. However, due to the restrictions of the core plug sizes and the pump pressures, the above findings may have certain limitations. Subsequent experimental studies will be conducted to supplement the existing results. Overall, the method of $\mathrm{SC}_{-} \mathrm{CO}_{2}$ jet breaking shale is valid and feasible.

\section{Conflicts of interest}

There are no conflicts to declare.

\section{Acknowledgements}

This work is jointly supported by the National Natural Science Foundation of China (No. 51804115 and 51604092), and the Natural Science Foundation of Hunan Province (No. 2017JJ3072).

\section{References}

1 S. Gou, T. Yin, Q. Xia and Q. Guo, RSC Adv., 2015, 5, 3206432071.

2 W. Chen, C. Zou, X. Li and L. Li, $R S C A d v ., 2016$, 6, 9068290689.

3 J. Xu, Z. Qiu, X. Zhao, T. Mou and H. Zhong, RSC Adv., 2018, 8, 20852-20861.

4 Y. Xuan, G. Jiang, Y. Li and X. Zhang, RSC Adv., 2015, 5, 84947-84958.

5 Phase diagram of carbon dioxide, Source: https:// www.chemicalogic.com.

6 H. Sun, W. Sun, H. Zhao, Y. Sun and D. Zhang, RSC Adv., 2016, 6, 32770-32778.

7 P. J. Jarboe, P. A. Candela, W. L. Zhu and A. J. Kaufman, Energy Fuels, 2015, 29, 7897-7909.

8 H. Wang, G. Li and Z. Shen, Energy Sources, 2012, 34, 14261435.

9 J. J. Kolle, SPE J., 2000, 65534.

10 Y. K. Du, R. H. Wang, H. J. Ni and M. K. Li, Journal of Hydrodynamics, 2012, 24, 554-560. 
11 H. Wang, G. Li, Z. Shen, S. Tian and B. Sun, J. Pet. Sci. Eng., 2015, 127, 305-310.

12 Q. Li and M. Jing, Chin. J. Rock Mech. Eng., 2013, 32, 22052213.

13 X. Guo, H. Ni, M. Li, L. Zhang and Y. Wang, Indian Geotech. J., 2018, 48, 1-8.

14 X. Zhang, Y. Lu, J. Tang, Z. Zhou and Y. Liao, Fuel, 2016, 190, 370-378.

15 Y. Hu, Y. Liu, C. Cai, Y. Kang and X. wang, Appl. Sci., 2017, 7, 1093.

16 Y. Lu, X. Ao, J. Tang, Y. Jia and X. Zhang, J. Nat. Gas Sci. Eng., 2016, 30, 268-275.

17 S. Zhang, X. Xian, J. Zhou and L. Zhang, RSC Adv., 2017, 7, 42946-42955.

18 S. Chen, Y. Zhu, H. Wang, H. Liu and W. Wei, Energy, 2011, 36, 6609-6616.

19 X. Zhao, J. Kang and B. Lan, Renewable Sustainable Energy Rev., 2013, 21, 603-613.

20 C. Yue, S. Li, H. Wen, F. Yang and X. Xu, RSC Adv., 2018, 8, 6436-6443.

21 M. Nasseri, F. Rezanezhad and R. Young, Int. J. Fract., 2011, 168, 1-13.

22 A. W. Momber, Wear, 2004, 256, 1190-1195.

23 Y. K. Du, R. H. Wang, H. Ni, H. J. Huo, Z. Huang, W. Yue, H. Zhao and B. Zhao, J. China Univ. Petrol., 2012, 36, 93-96. 24 J. E. Field, Wear, 1999, 233, 1-12.

25 S. S. Cook, Proc. R. Soc. London, Ser. A, 1928, 119, 418-488.
26 R. Lahann, M. Mastalerz, J. Rupp and A. Drobniak, Int. J. Coal Geol., 2013, 108, 2-9.

27 M. Angeli, M. Soldal, E. Skurtveit and E. Aker, Energy Procedia, 2009, 1, 3351-3358.

28 M. Allawzi, A. Al-Otoom, H. Allaboun, A. Ajlouni and F. A. Nseirat, Fuel Process. Technol., 2011, 92, 2016-2023.

29 T. F. Xu, J. A. Apps and K. Pruess, Chem. Geol., 2005, 217, 295-318.

30 J. Tang, Y. Lu, Y. Chen, X. Zhang, X. Ao, Y. Jia and Q. Li, Rock Soil Mech., 2018, 39, 797-802.

31 B. L. Alemu, P. Aagaard, I. A. Munz and E. Skurtveit, Appl. Geochem., 2011, 26, 1975-1989.

32 C. Fouillac, B. Sanjuan, S. Gentier and I. CzernichowskiLauriol, Third Annual Conference on Carbon Capture and Sequestration, Alexandria, VA, May 3-6, 2004.

33 A. Busch, S. Alles, Y. Gensterblum, D. Prinz and D. N. Dewhurst, Int. J. Greenhouse Gas Control, 2008, 2, 297-308.

34 J. Wollenweber, S. Alles, A. Busch, B. M. Krooss and H. Stanjek, Int. J. Greenhouse Gas Control, 2010, 4, 231-241.

35 T. R. Elliot and M. A. Celia, Environ. Sci. Technol., 2012, 46, 4223-4227.

36 F. P. Bowden and J. E. Field, Proc. R. Soc. London, Ser. A, 1964, 282, 331-352.

37 Y. Zhao, L. Zhang, W. Wang, W. Wan and S. Li, Rock Mech. Rock Eng., 2017, 50, 1-16.

38 M. V. Swain and J. T. Hagan, J. Mater. Sci., 1980, 15, 387-404. 